\title{
BMJ Open Identifying research priorities in cardiac surgery: a report from the James Lind Alliance Priority Setting Partnership in adult heart surgery
}

\author{
Florence Y Lai (D) , Riccardo G Abbasciano, Bethany Tabberer, Tracy Kumar, \\ Gavin J Murphy, Steering Group of the James Lind Alliance Heart Surgery Priority \\ Setting Partnership
}

To cite: Lai FY, Abbasciano RG, Tabberer B, et al. Identifying research priorities in cardiac surgery: a report from the James Lind Alliance Priority Setting Partnership in adult heart surgery. BMJ Open 2020;10:e038001. doi:10.1136/ bmjopen-2020-038001

- Prepublication history for this paper is available online. To view these files, please visit the journal online (http://dx.doi org/10.1136/bmjopen-2020038001).

Received 24 February 2020 Revised 14 May 2020 Accepted 19 July 2020
Check for updates

(C) Author(s) (or their employer(s)) 2020. Re-use permitted under CC BY-NC. No commercial re-use. See rights and permissions. Published by BMJ.

Department of Cardiovascular Sciences and NIHR Leicester Biomedical Research Unit in Cardiovascular Medicine, University of Leicester, Leicester, UK

Correspondence to Prof Gavin J Murphy; gjm19@le.ac.uk

\section{ABSTRACT}

Objective To identify research priorities that address the needs of people affected by cardiac surgery and those who support and care for them.

Design James Lind Alliance (JLA) process - two surveys and a consensus workshop guided by an independent JLA adviser.

Setting The UK with international participation. Participants Three stakeholder groups-heart surgery patients, carers and healthcare professionals involved in care delivery.

Methods The initial survey was set to collect potential research questions in cardiac surgery as identified by stakeholders. Submitted questions were summarised into indicative questions. The existing evidence was searched to verify that these indicative questions had not been answered. In the second survey, stakeholders then voted for their top 10 from the list of unanswered questions. The top voted questions were taken forward for final ranking in a workshop.

Results In the initial survey, 629 respondents (28\% patients/carers, $62 \%$ healthcare professionals) submitted 1082 potential questions. Of these, 797 in-scope questions were summarised into 49 indicative questions and of which 45 had not been answered by existing research. In the second survey, 492 respondents (43\% patients/ carers, $49 \%$ healthcare professionals) cast their votes with the top 12 from each of the three stakeholder groups totalling 21 questions advancing to the final priority setting workshop. The workshop attended by 25 delegates (10 patients/carers and 15 healthcare professionals) agreed on the top 10 research questions including long-term outcomes (quality of life), and aspects from preoperative personalised care (prehabilitation, frailty, comorbidities), intraoperative management (minimally invasive techniques), to prevention and management of postoperative complications (organ injury, atrial fibrillation, infection).

Conclusions This Priority Setting Partnership (PSP) identified the priorities and unmet needs of patients and clinicians in cardiac surgery. The next step is to disseminate and implement the PSP results to ensure that these priorities shape future research and improve clinical services.

\section{Strengths and limitations of this study}

- Large number of stakeholders involved making the Priority Setting Partnership the largest patient and public involvement exercise in the UK in setting the research agenda for cardiac surgery.

- The process was consensus based and transparent with all stakeholder groups (patients, carers and healthcare professionals) being equal in contributing to the decision-making throughout.

- Considerable effort was made to reach out to different patient groups and professional bodies to collect their responses; despite this, certain groups including patients from ethnic minority backgrounds might be under-represented.

- The 10 priorities were identified reflecting the balance of views by the stakeholder groups in the final workshop; we cannot exclude that on a different day, or with a different make-up of the delegates, the selected top 10 may be different.

\section{INTRODUCTION}

Approximately 35000 cardiac surgery procedures are carried out in the UK each year ${ }^{12}$ with a total annual healthcare spend of close to $£ 0.5$ billion. Cardiac surgery is undergoing a period of transition. Patients referred for cardiac surgery are increasingly older, often have multiple chronic conditions and require more complex surgery than historical cohorts. In addition, potentially better diagnostic tests, less invasive treatments and new devices are being introduced into clinical care at an accelerated rate. In order to adapt to these changes and deliver the best quality personalised care to these patients, high-quality research evidence is needed. It is only through this evidence that we will be able to direct the right care to the right individual patient at the right time.

Focusing research efforts to areas of greatest need benefits from the identification 
of an agreed set of national research priorities developed through a clear process of consultation and stakeholder engagement. The rigorous James Lind Alliance (JLA) process fulfils many of the criteria defined for good practice of research priority setting. ${ }^{3}$ Commissioned by the Society for Cardiothoracic Surgery in Great Britain and Ireland, and funded by Heart Research UK, a JLA Priority Setting Partnership (PSP) in adult heart surgery was established in November 2017. The aims of the partnership were, first, to identify the areas of clinical uncertainty that are most important to those affected by cardiac surgery, including front-line clinicians, patients and those who care for them, and second, to prioritise these research questions to inform researchers as well as strategic decisions made by research funders.

\section{METHODS}

The PSP was conducted between January 2018 and September 2019 in accordance with the JLA guidelines. ${ }^{45}$ This included:

1. The set-up of a multistakeholder Steering Group, led by an independent chairwoman appointed by the JLA, who defined and agreed the scope of the PSP, and who provided oversight for the entire process.

2. Completion of an initial survey to collect a long list of potential research questions.

3. The collation and, where necessary, the assimilation of submitted questions to form indicative questions.

4. Checking the list of submitted questions against available evidence and published guidelines to verify the uncertainties and compile a long list of research topics.

5. Completion of a second survey to allow stakeholders to identify their top 10 indicative questions from the long list.

6. Collation of the second survey results with selection of a shortlist of questions prioritised by patients, carers and healthcare researchers.

7. A priority setting workshop undertaken by all stakeholders to select the top 10 research questions.

8. A dissemination programme which comprised multimedia communications and presentation at national and international conferences.

\section{Set-up}

A Steering Group with 24 volunteers including 7 patients and carers/family members, 13 healthcare professionals (clinicians, pharmacists, nurses and other allied health professionals), 1 representative from the East Midlands Centre for Black and Minority Ethnic Health and 3 experts in information management and evidence synthesis (Data Team) was established to oversee the development of the PSP. The Steering Group was chaired by a JLA adviser and supported by a Project Team of administrative staff.

At the first Steering Group meeting held in January 2018, the protocol and terms of reference for the PSP were agreed. ${ }^{6}$ The Steering Group also defined the scope of the PSP, which encompassed all aspects of clinical research in adult cardiac surgery including postcardiotomy extracorporeal support. However, cardiopulmonary transplantation and surgery that considers the use of devices to treat heart failure were excluded, as the treatment of these patients is separate from the generality of adult cardiac surgery in the UK, with distinct multidisciplinary teams, and specific research initiatives linked to NHS Blood and Transplant. Also, the PSP did not consider research in children undergoing cardiac surgery as they primarily present with congenital cardiac diseases, and have different physiology to adults with different clinical concerns. It was felt that a separate PSP for paediatric cardiac surgery is required to capture the research priorities in this discipline. For this reason, surgery for grown-up congenital heart diseases was not included. Furthermore, this PSP was primarily focused on clinical research questions that would be addressed by clinical trials or clinical research programmes, although the priority questions should not undermine the crucial role of basic science research in the generation of new knowledge that precedes clinical evaluation.

\section{Initial survey}

An online questionnaire was created to collect potential research questions along with demographics of the respondents. The survey was open ended asking "what questions about heart surgery would you like to see answered by research?' The survey was open to patients (who have heart surgery, those with a heart condition and waiting for surgery) and their caregivers as well as healthcare professionals including cardiac surgeons, anaesthetists, intensivist, nurses and allied health involved in the care delivery of heart surgery.

It has been reported that the method of administration shows an impact on survey responses. ${ }^{7}$ To improve access and reduce response bias, the survey was also administered in paper form. Returned paper questionnaires were entered into the online survey by the Project Team so that all responses were kept in one database.

The initial survey was promoted through the Steering Committee's networks and using social media such as Facebook and Twitter, booths at academic conferences as well as emailing and distributing leaflets to professional bodies. Flyers and questionnaires were distributed at outpatient clinics and scientific conferences in the UK. Digital methods were found to be helpful when reaching out to patient support groups and international professional networks, including those in Australia and New Zealand, Europe and North America.

\section{Processing submitted questions}

All submissions were downloaded into an Excel spreadsheet and reviewed by the information specialists in the Data Team. Out-of-scope questions (defined earlier in the set-up including heart transplant and paediatric cardiac surgery) or questions that could not be framed as a research question for cardiac surgery were identified. These include questions that are too broad (eg, how to 
prevent a heart condition; can the side effects of cardiovascular drugs be reduced) or questions that are not related to cardiac surgery (eg, why patients with diabetes are at risk of developing a heart condition). These questions were reviewed by the Steering Group and were excluded if the members agreed. The remaining questions were tagged by keywords, which were then used to group the questions into themes including: (A) patient selection/ risk stratification; (B) preoperative and postoperative care/lifestyle advice; (C) anaesthetic management; (D) intraoperative management; (E) postoperative complications and management; (F) long-term outcomes; $(\mathrm{G})$ valve surgery; $(\mathrm{H})$ coronary artery bypass graft $(\mathrm{CABG})$; (I) specific disease conditions; and (J) others.

Tagging and grouping of submitted questions was initially performed by the Data Team, and the results were reviewed and discussed by the Steering Group at a face-to-face meeting in November 2019. All members were given opportunities to comment on the process and ensured that the submitted questions were interpreted and captured correctly in the summarised questions. Also the questions were worded with the language that is accessible to non-medical audiences but also accurate enough to engage healthcare professionals. At the end of the meeting, the Steering Group agree on the list of summarised indicative questions.

The Data Team then conducted literature searches to check whether any questions on the list had been appropriately answered by high-quality randomised controlled trials or systematic reviews. Indicative questions were checked against the Cochrane Database of Systematic Reviews ${ }^{8}$ because of their recognised methodological rigour, and clinical guidelines from UK National Institute for Health and Care Excellence, Scottish Intercollegiate Guidelines Network, American Heart Association, Society for Thoracic Surgeons, European Society of Cardiology, European Association for Cardio-Thoracic Surgery, and European Society of Anaesthesiology. With advice from an experienced information advisor, a separate search strategy was developed for each evidence source using the terms including cardiac, heart, $C P B$, cardiopulmonary bypass, aorta, coronary, $C A B G$, revascularization, valve, mitral and aortic, with a time frame restricted to the last 5 years. The time restriction we applied to the searches reflected the deep changes cardiac surgery has undergone in the recent period. ${ }^{9}$ The Data Team conducted the searches during December 2018 to January 2019 and reviewed all the identified information. Relevant literature was collated for each indicative question, and the results were reviewed by the Steering Group to decide if enough current evidence was available to categorise a question as answered.

\section{Second survey}

All indicative questions that had not been fully addressed by existing research became the long list of questions and were entered into the second survey for patients, carers and health professionals to vote on. People were asked to select up to 10 questions they felt were the most important. As in the initial survey, the second survey was administered in both online and paper forms, and was promoted through the Steering Committee's networks as well as social media such as Facebook and Twitter and booths at academic conferences in the UK.

The votes for each question were summed individually for each group of respondents. Respondents who selected more than 10 questions had their 10 votes equally split among the selected questions; for example, if a respondent voted for 12 questions, each question selected was awarded 0.83 to be summed. The Steering Group then selected the top 10-15 scored questions from each of the three respondent groups to take forward for the final priority setting workshop. A shortlist of 20-25 questions for the final workshop was considered desirable. We did not use aggregated ranking across respondent groups so that the priority questions selected by individual stakeholder groups would all be included.

\section{Priority setting workshop}

The aim of the workshop was to establish the top 10 questions, from the shortlist of questions, for cardiac surgery research by general consensus of all participants or by majority votes where consensus could not be reached. To ensure the outcomes reflect the national research interests, it was important that the workshop was attended by representatives from all three stakeholder groups (patients, carers and healthcare professionals) across the UK. Based on the experience from previous PSPs, the JLA advised around 25 participants for the workshop would allow the best interaction.

The priority setting workshop was conducted based on the nominal group technique ${ }^{10}$ with three rounds of discussion. In the first round, three working groups each with equal representation from the three stakeholder groups were formed. The working groups were working separately to rank the shortlisted questions. A JLA facilitator was assigned to each working group to facilitate the discussion. The rankings produced by each of the three working groups were entered into an Excel worksheet and an aggregated ranked list was produced. A further working group round took place with three new working groups. Each group reviewed and discussed the aggregated ranking to come up with the group's priorities. The results were then collated and discussed in one combined plenary session, moderated by a JLA adviser, the chairman of the Steering Group. All participants were given opportunity to voice their reasoning for/against a priority to appear in the final ranking. The adviser ensured that all participants contributed equally and no one group or individuals dominated the prioritisation. At the end of the plenary session, the final top 10 was agreed as priorities for future research.

\section{Dissemination}

Following the finalisation of the research priorities, a dissemination plan was developed which included 


\begin{tabular}{|c|c|c|}
\hline & Initial survey & Second survey \\
\hline Respondents (n) & 629 & 492 \\
\hline \multicolumn{3}{|l|}{ Type (\%) } \\
\hline Patients & $130(21)$ & 159 (32) \\
\hline Carers & $43(7)$ & $54(11)$ \\
\hline Healthcare professional & $389(62)$ & 241 (49) \\
\hline Doctors & $284(45)$ & $135(27)$ \\
\hline Nurse & $72(11)$ & $57(12)$ \\
\hline Allied health & $30(5)$ & $31(6)$ \\
\hline $\begin{array}{l}\text { Others }{ }^{*} \text { and not } \\
\text { specified }\end{array}$ & $67(10)$ & $38(8)$ \\
\hline
\end{tabular}

*Mostly scientists, researchers and students.

newsletters, a web page, publication via the JLA website, presentation at scientific conferences and public engagement events, and through social media. Members of the Steering Group agreed to take a proactive role in disseminating the results within their patient groups or professional networks.

\section{Patient and public involvement}

Patient and public involvement (PPI) was involved at every stage of the Heart Surgery PSP. Members of the Steering Group included representatives of cardiac surgery patients and their caregivers, and they were responsible for overseeing and guiding the activity throughout the process.

\section{RESULTS \\ Initial survey}

The initial survey was launched at the 2018 annual meeting of the Society for Cardiothoracic Surgeons in the UK and Ireland, and was conducted between March and November 2018. The survey results included 1082 questions from 629 respondents, of whom $21 \%$ were patients, $7 \%$ carers, $62 \%$ healthcare professionals and $10 \%$ others / not stated (table 1). Of the healthcare professionals who specified their role, $73 \%$ were clinicians, $19 \%$ nurses and $8 \%$ allied health professionals reflecting the multidisciplinary nature of the heart surgery team. The age distributions of the respondents were as expected with the majority of patients and carers aged 50 and above and healthcare professionals within working age (table 2). A large proportion of respondents did not provide their ethnicity. Based on the available data, respondents were predominantly white in all groups, with minority ethnic groups which appear to be under-represented in carer samples.

All 1082 submitted questions were reviewed by the Data Team. After excluding 162 out-of-scope questions, 33 non-questions and 90 others which could not be framed as a research question for clinical research, 797 questions remained. Figure 1 summarises the type of the in-scope questions. The most common questions submitted by

Table 2 Demographics of respondents in the initial and second surveys

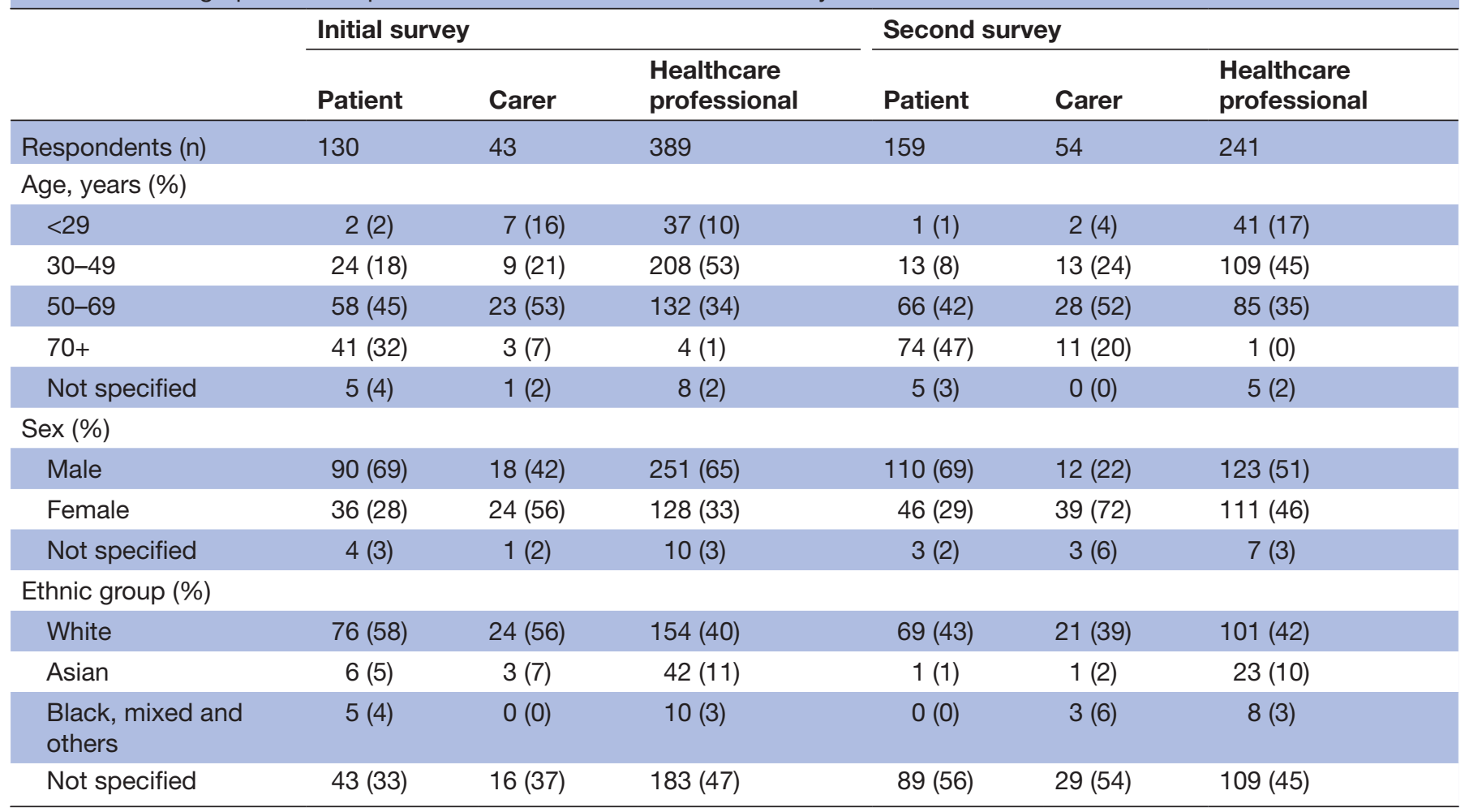




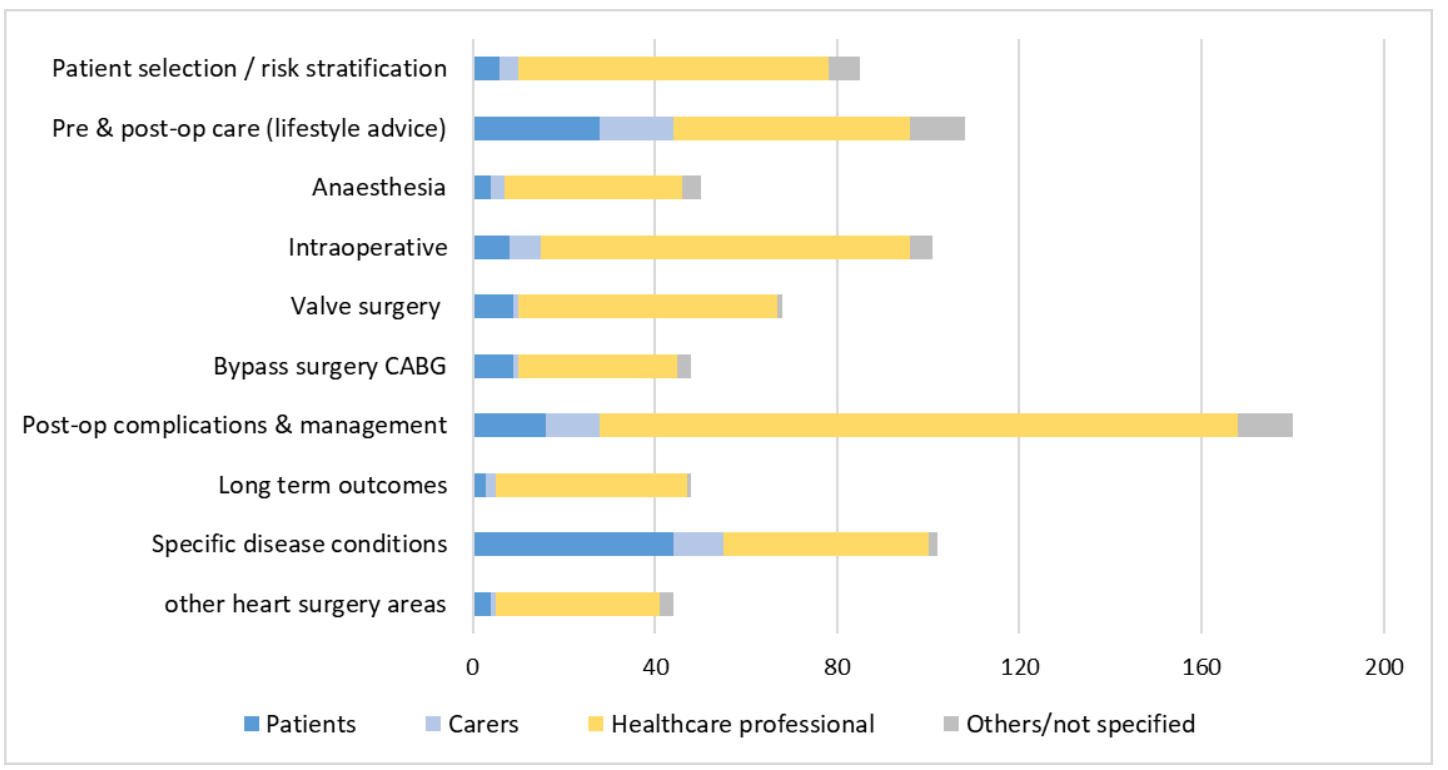

Figure 1 Classification of submitted in-scope questions in the initial survey. CABG, coronary artery bypass graft.

patients and carers related to specific disease conditions (particularly aortic dissection), followed by preoperative and postoperative lifestyle advice. The most common questions submitted by healthcare professionals were related to intraoperative and postoperative management.

The in-scope questions were initially grouped and summarised into 72 indicative questions by the Data Team. After reviewing by the members of the Steering Committee in a face-to-face meeting held on 22 November 2018, these questions were further aggregated and summarised into 49 indicative questions. Subsequent literature review indicated that four of these questions have been adequately answered by existing research, thus 45 questions were taken forward for voting in the second survey.

\section{Second survey: voting}

The second survey was launched at the 2019 annual meeting of Society for Cardiothoracic Surgeons in the UK and Ireland, and was conducted between March and June 2019. The second survey received a total of 492 responses from patients $(32 \%)$, carers $(11 \%)$, healthcare professionals $(49 \%)$ and others $(8 \%)$ (table 1). Compared with the initial survey, respondents who were healthcare professionals remained as the majority although by proportion the percentage from patients and carers increased ( $43 \%$ second survey vs $28 \%$ initial survey). Patient demographics in terms of age and sex were broadly similar in the two surveys. However, ethnic minority groups were relatively under-represented in the patient samples (table 2).

Votes from each of the three respondent groups (patients, carers and healthcare professionals) were counted separately. Votes from others were excluded. The top 12 ranked questions from each group resulting in a total of 21 questions were taken forward for the final workshop.
Patients and carers voted highly on long-term outcomes and lifestyle adaptation before/after surgery, while healthcare professionals voted highly on management of patients with chronic conditions and the effectiveness of specific clinical programmes including prehabilitation and enhanced recovery after surgery. Both patients and healthcare professionals ranked research into quality of life and minimally invasive surgery techniques as very important (table 3 ).

\section{Final priority setting workshop}

The priority setting workshop was held at Leicester on 11 July 2019 and attended by 25 delegates consisting of 11 patients/carers and 14 healthcare professionals. The group had fair and balanced representation from all stakeholder groups. The workshop was hosted and run by four independent moderators appointed by the JLA. Heart charities, professional societies, research funders and patient organisations were also present as non-voting and independent observers. The final top 10 priority research questions were agreed by all representatives attending the workshop (table 4).

The top research priority was improving long-term quality of life for cardiac surgery patients. Next were the management strategies of specific patient groups (frail patients, patients with chronic conditions) and the role of prehabilitation programmes. Two of the top 10 questions centred on research into surgical interventions (timing of heart valve surgery and minimally invasive heart surgery techniques), and three questions were related to the prevention and management of postoperative complications (organ injury, atrial fibrillation and infection). The top 10 priorities were comprehensive, addressed all the common diseases that are treated by cardiac surgery, and all phases of the patient journey from preoperative care and risk stratification, intraoperative management, 
Table 3 Rankings of the shortlist of questions in the second survey and the final workshop

\begin{tabular}{|c|c|c|c|c|}
\hline \multirow[b]{2}{*}{ Question } & \multirow[b]{2}{*}{$\begin{array}{l}\text { Workshop } \\
\text { final ranking }\end{array}$} & \multicolumn{3}{|c|}{ Second survey ranking } \\
\hline & & Patients & Carers & $\begin{array}{l}\text { Healthcare } \\
\text { professional }\end{array}$ \\
\hline $\begin{array}{l}\text { How does a patient quality of life (QOL) change (eg, disability-free } \\
\text { survival) following heart surgery and what factors are associated } \\
\text { with this? }\end{array}$ & 1 & 4 & 10 & 1 \\
\hline $\begin{array}{l}\text { How can we address frailty and improve the management of frail } \\
\text { patients in heart surgery? }\end{array}$ & 2 & 39 & 36 & 7 \\
\hline $\begin{array}{l}\text { How can we improve the outcomes of heart surgery patients with } \\
\text { chronic conditions (obesity, diabetes, hypertension, renal failure, } \\
\text { autoimmune diseases, and so on)? }\end{array}$ & 3 & 13 & 6 & 3 \\
\hline $\begin{array}{l}\text { Does prehabilitation (a programme of nutritional, exercise and } \\
\text { psychological interventions before surgery) benefit heart surgery } \\
\text { patients? }\end{array}$ & 4 & 27 & Joint 27 & 2 \\
\hline $\begin{array}{l}\text { When should heart valve intervention occur for patients without } \\
\text { symptoms? }\end{array}$ & 5 & 26 & 11 & 27 \\
\hline $\begin{array}{l}\text { How does minimally invasive heart surgery compare to traditional } \\
\text { open surgery? }\end{array}$ & 6 & 3 & 3 & 6 \\
\hline $\begin{array}{l}\text { How do we minimise damage to organs from heart-lung machine/ } \\
\text { heart surgery (heart, kidney, lung, brain and gut)? }\end{array}$ & 7 & 23 & 21 & 8 \\
\hline $\begin{array}{l}\text { Can we use 3D bioprinting or stem cell technology to create living } \\
\text { tissues (heart valves/heart) and repair failing hearts (myocardial } \\
\text { regeneration)? }\end{array}$ & 8 & 12 & 8 & 17 \\
\hline $\begin{array}{l}\text { What are the most effective ways of preventing and treating } \\
\text { postoperative atrial fibrillation? }\end{array}$ & 9 & 6 & 25 & 9 \\
\hline $\begin{array}{l}\text { How do we reduce and manage infections after heart surgery } \\
\text { including surgical site/sternal wound infection and pneumonia? }\end{array}$ & 10 & 11 & Joint 27 & 21 \\
\hline $\begin{array}{l}\text { Does enhanced recovery after surgery (ERAS) improve outcomes in } \\
\text { heart surgery? }\end{array}$ & & 10 & Joint 13 & 4 \\
\hline $\begin{array}{l}\text { What are the long-term outcomes, including life expectancy, after } \\
\text { heart surgery? }\end{array}$ & & 1 & 1 & 5 \\
\hline What are the benefits of heart surgery in older patients? & & 14 & 9 & 11 \\
\hline $\begin{array}{l}\text { What are the best cardiovascular medications for management in } \\
\text { heart surgery (eg, ACE inhibitors, antiplatelet, anticoagulant)? }\end{array}$ & & 8 & Joint 13 & 36 \\
\hline $\begin{array}{l}\text { What are the best ways to prevent, diagnose and treat patients with } \\
\text { acute aortic dissection (including long-term management)? }\end{array}$ & & 7 & 4 & 16 \\
\hline $\begin{array}{l}\text { What is the best strategy for managing acute heart failure after } \\
\text { heart surgery (inotropic drug, mechanical support or intravascular } \\
\text { devices)? }\end{array}$ & & 36 & 38 & 12 \\
\hline $\begin{array}{l}\text { How do transcutaneous techniques for heart valve surgery compare } \\
\text { to traditional open surgery (TAVI vs AVR)? }\end{array}$ & & 30 & 7 & 10 \\
\hline $\begin{array}{l}\text { What can patients do (in terms of their lifestyle choices-exercise, } \\
\text { diet, smoking, well-being, and so on) before and after heart surgery } \\
\text { to improve outcomes? }\end{array}$ & & 2 & 2 & 18 \\
\hline $\begin{array}{l}\text { How can we improve the communication between the medical } \\
\text { team and patients/carers regarding the risks and benefits of heart } \\
\text { surgery? }\end{array}$ & & 5 & 5 & 26 \\
\hline $\begin{array}{l}\text { Does having access to specialist cardiac nurses or consultants by } \\
\text { electronic methods improve outcomes for heart surgery patients? }\end{array}$ & & 24 & 12 & 41 \\
\hline $\begin{array}{l}\text { Do outcomes of heart surgery and follow-up time vary by postcode/ } \\
\text { location and how to reduce the variation? }\end{array}$ & & 9 & 31 & 43 \\
\hline
\end{tabular}

AVR, aortic valve replacement; TAVI, transcatheter aortic valve implantation. 
Table 4 Top 10 priority research questions for adult heart surgery

\begin{tabular}{|c|c|}
\hline Ranking & Question \\
\hline 1 & $\begin{array}{l}\text { How does a patient quality of life (QOL) change (eg, disability-free survival) following heart surgery and what factors } \\
\text { are associated with this? }\end{array}$ \\
\hline 3 & $\begin{array}{l}\text { How can we improve the outcomes of heart surgery patients with chronic conditions (obesity, diabetes, } \\
\text { hypertension, renal failure, autoimmune diseases, and so on)? }\end{array}$ \\
\hline 4 & $\begin{array}{l}\text { Does prehabilitation (a programme of nutritional, exercise and psychological interventions before surgery) benefit } \\
\text { heart surgery patients? }\end{array}$ \\
\hline 5 & When should heart valve intervention occur for patients without symptoms? \\
\hline 6 & How does minimally invasive heart surgery compare to traditional open surgery? \\
\hline 7 & How do we minimise damage to organs from heart-lung machine/heart surgery (heart, kidney, lung, brain and gut)? \\
\hline 8 & $\begin{array}{l}\text { Can we use 3D bioprinting or stem cell technology to create living tissues (heart valves/heart) and repair failing } \\
\text { hearts (myocardial regeneration)? }\end{array}$ \\
\hline
\end{tabular}

to immediate postoperative, short-term and long-term outcomes.

\section{Results dissemination}

The results along with key documents for this PSP are accessible on the JLA website,http:/ /www.jla.nihr.ac.uk/ priority-setting-partnerships/heart-surgery. This includes the protocol, the survey questionnaires, the long list of 45 questions for voting, the shortlist of 21 questions for final prioritisation and reports on the results and a plan for translating the research priorities into clinical studies. Other reports have been produced to publicise the results as widely as possible. ${ }^{111}$ Presentation of the PSP results is also planned for relevant scientific meetings.

It is important to recognise that while the JLA process provides a set of priorities for research agenda, the output questions are best described as topics or areas that are important to those affected by cardiac surgery, rather than specific research questions ready for funding. To help implement the PSP results, collaborative works with researchers and funders are needed to translate the priorities into specific clinical research questions. As a first step, in collaboration with Cochrane Heart, a series of systematic reviews of the priority research questions will be commissioned. These will more fully define knowledge gaps that can be addressed by clinical trials. In addition, a national Clinical Research Priorities Workshop, sponsored by Heart Research UK and the British Heart Foundation Clinical Research Collaborative, is being planned for early 2021. This 1 day workshop will bring together patients, carers, clinicians and leading researchers to form interdisciplinary working groups who will consider individual priority areas in depth with the aim of translating these into high-quality clinical trials.

\section{DISCUSSION}

Patient-centred care has become a focus for healthcare teams and research funders. ${ }^{13}$ Using the JLA process, this PSP identified the top 10 research questions in cardiac surgery, as determined by people who are mostly affected by the surgery-patients, carers and healthcare professionals involved in the heart team. The PSP engaged multiple patient networks and professional bodies, and attracted a total of over 1000 submissions across two surveys. The final workshop was attended by 25 delegates representing patients, carers and healthcare professionals. To our knowledge this is the largest PPI exercise in the UK focusing on research priorities in cardiovascular diseases.

Throughout the process, there were clear preferences for different stakeholder groups. For example, patients and carers placed greater emphasis on long-term outcomes, lifestyle adaptation before and after surgery, and improving communication between medical staff and patients and their families; while healthcare professionals voted predominantly for research into the management of frailty and patients with chronic conditions, prehabilitation, organ protection and infection prevention. The question on 'How can we improve the communication between the medical team and patients/carers regarding the risks and benefits of heart surgery?' was a preference for patients and carers. It was clear in the workshop that some patient representatives felt strongly about clinician training to improve communication; but other patients and clinicians argued that medical training includes a component on communication, and such skill is important across all medical disciplines, not just cardiac surgery. This question did not make it to the top 10 as it was agreed by the majority in the workshop that within the limit of 10 priorities, other questions were more important. Conversely research into the diagnosis and 
treatment of thoracic aortic disease was more popular with clinicians but was not on the final top 10 . This attests to the transparency and fairness of the process that no one stakeholder group was dominant in the priority setting.

This PSP was primarily focused on research questions that would be addressed by clinical trials or other clinical studies. It did not consider early phase translational research or technology transfer. However, one top 10 question, priority 8 , related to three-dimensional bioprinting and stem cell technology highlights the crucial role of basic science research in the future of cardiac surgery.

There were challenges when implementing the surveys. Due to the open-ended nature of the initial survey, many patients and carers found it hard to propose any research questions citing the reasons that they had received the care deemed excellent (thereby no gaps in knowledge that demands further research) or they felt they did not have sufficient knowledge to volunteer a question. Unlike other PSPs, for instance diabetes, where patients often manage their chronic conditions on a day-to-day basis with their doctors, cardiac surgery patients receive complex major surgery within a high-dependency hospital setting. This presents barriers to patient participation in the development of research priorities. As the aim of the PSP was to bridge the gap between researchers and patients, the Project Team adopted multiple approaches to increase the participation of patients and carers and ensure the access to the survey was as user friendly as possible. We talked to cardiac surgery patients on the wards and encouraged them to use their own experiences and concerns regarding their patient journey to frame their research questions. In some cases where respondents described personal experience and themes/issues, the Project Team would then convert these into indicative questions. This process was agreed by the Steering Group. For example, a patient put down 'After bypass surgery, what is my life expectancy?' This became the research question, 'What is the life expectancy after heart surgery?' Another example, 'After surgery, no consideration for mental wellbeing.' This was interpreted as a need for research into mental health problems after surgery.

Both the initial and the second surveys were administered in paper-based and web-based formats. This encouraged participation from people who have preference for one or other of these formats. In addition, when distributing the flyers and paper-based questionnaires at outpatient clinics and scientific conferences, a printed QR code was also provided for direct access to the online surveys with mobile devices. The Project Team adopted various digital platforms (Facebook, Twitter) and emailing to reach out to multiple patient support groups and professional bodies in the UK and internationally.

The finalisation of the top 10 research questions should not be seen as project completion but as a beginning. The PSP results need to be disseminated and promoted among the wider research community. As the research priorities identified through the JLA process typically represent broad areas that are important to the stakeholders, further steps working collaboratively with researchers and funders are needed to turn the priorities into funded research. The Heart Surgery PSP is planning a workshop to discuss individual research priorities in details. Similar knowledge translation workshop has also been implemented by other PSPs such as the Teenage and Young Adult Cancer PSP.

The Heart Surgery PSP included a large sample size, with 629 respondents in the initial survey and nearly 500 respondents in the second survey. Considerable effort was made by the members of the Steering Group to engage patients and healthcare professionals via their connections. The Project Team adopted multiple approaches to reach out to different patient groups and professional bodies. Despite all the efforts, ethnic minority groups appeared to be under-represented in certain patient and carer samples. In addition, the top 10 priorities were identified reflecting the balance of views by the stakeholder groups in the final workshop; we cannot exclude that on a different day, or with a different make-up of the delegates, the selected top 10 may be different. Furthermore, research priorities in cardiac surgery can be very dynamic and may change over time as new treatments, new surgical techniques or new diagnostic tests are developed and introduced into clinical care.

In conclusion, this PSP identified research priorities that address the needs of those affected by cardiac surgery and those who support and care for them. The process was transparent and fair, with all stakeholders being equal in sharing their thoughts and contributing to the setting of the priority questions. The next step is the dissemination of the PSP results and the development of implementation plans to ensure that these priorities shape future research and improve clinical services.

Acknowledgements The Steering Group would like to thank the contributions from all of the patients, carers and healthcare professionals who provided research questions and voted on the priority of these questions in two surveys. We thank the delegates of the final workshop for sharing their view and achieving an agreement on the priority research questions for heart surgery. We also thank the James Lind Alliance for their guidance throughout the process.

Collaborators Steering Group of the James Lind Alliance Heart Surgery Priority Setting Partnership. All members of the Steering Group and the Project Team are authors including Anthony Locke, Leicestershire Cardiac Surgery Patient and Public Involvement Group, NIHR Senior PPI panel; Peter Read, Leicester Cardiac Surgery PPI Group; Trevor Fernandes, Cardiovascular Care Patients (CPPUK) and Wider Community Patient Links; Richard Fitzgerald, Cardiovascular Care Patients (CPPUK) and Wider Community Patient Links; Zena Jones, patient representative, Health Watch County Durham; Jonathan Stretton-Downes, Six Times Open; Grace Stretton-Downes, family member representative; Professor Gavin Murphy, BHF Chair of Cardiac Surgery, University of Leicester, Society for Cardiothoracic Surgery in Great Britain and Ireland, Academic and Research Committee Chair; Mr Peter Braidley, Consultant Cardiac Surgeon, Sheffield University Hospitals, Heart Research UK Trustee; Mr Enoch Akowuah, Consultant Cardiac Surgeon, James Cook Hospital, Middlesbrough, member of the British Cardiac Society, Heart Valve Clinical Studies Group; Professor Julie Sanders, Director Clinical Research, St Bartholomew's Hospital, Barts Health NHS Trust and Society for Cardiothoracic Surgery in Great Britain and Ireland (SCTS) nursing and AHP academic lead; Professor John Pepper, Professor of Cardiothoracic Surgery, Imperial College London; Professor Andrew Klein, Mackintosh Professor of Anaesthesia, Royal Papworth Hospital NHS Trust, Association of Cardiothoracic Anaesthesia Research Subcommittee Chair; Harpal Ghattoraya, Research Delivery Manager, NIHR Clinical Research Network; Professor Stephen Clark, Professor of Cardiothoracic Surgery and Cardiopulmonary 
Transplantation, Freeman Hospital, Newcastle; Professor Mahmoud Loubani, Honorary Professor of Cardiothoracic Surgery, University of Hull; Mr David Jenkins, Consultant Cardiac Surgeon, Papworth Hospital Cambridge; Dr Nazish Khan, Principal Pharmacist Cardiac Services, The Royal Wolverhampton Hospitals NHS Trust; Professor Rod Stables, British Cardiovascular Society, Academic and Research Committee Chair; Carol Akroyd, East Midlands Centre for BME Health and CLAHRC Prevention Theme Manager; Mr Ricky Vaja, Associate Surgical Specialty Lead Cardiothoracic Surgery, Royal Brompton and Harefield NHS Trust; Mr Luke Rogers, Associate Surgical Specialty Lead Cardiothoracic Surgery, Derriford Hospital; Katherine Cowan (Chair, JLA Senior Adviser); as well as the following from the University of Leicester: Tracy Kumar, Senior Research Manager; Sue Page, PA to Professor Gavin Murphy; Hardeep Aujla, Clinical Trial Coordinator; Bethany Tabberer Clinical Trials Administrator; Carrie Ackrill, PSP Administrator; Clare Gillies, Lecturer in Health Statistics; Selina Lock, Library Research Services Consultant; Florence Lai, Senior Statistician; and Riccardo Abbasciano, Clinical Research Fellow.

Contributors FYL, RGA and BT were involved in collection and analysis of data. TK and GJM made substantial contributions to the conception and implementation of the PSP and interpretation of data. All authors were responsible for overseeing and guiding the activity throughout the PSP process. The manuscript was drafted by FYL and all authors have read, critically reviewed and approved the final version of the manuscript.

Funding The Heart Surgery PSP was funded by Heart Research UK.

Competing interests None declared.

Patient and public involvement Patients and/or the public were involved in the design, or conduct, or reporting, or dissemination plans of this research. Refer to the Methods section for further details.

Patient consent for publication Not required.

Provenance and peer review Not commissioned; externally peer reviewed.

Data availability statement Data are available in a public, open access repository. Key documents and data are accessible on the JLA website, http://www.jla.nihr.ac. uk/priority-setting-partnerships/heart-surgery

Open access This is an open access article distributed in accordance with the Creative Commons Attribution Non Commercial (CC BY-NC 4.0) license, which permits others to distribute, remix, adapt, build upon this work non-commercially, and license their derivative works on different terms, provided the original work is properly cited, appropriate credit is given, any changes made indicated, and the use is non-commercial. See: http://creativecommons.org/licenses/by-nc/4.0/.

\section{ORCID iD}

Florence Y Lai http://orcid.org/0000-0003-4354-0624

\section{REFERENCES}

1 SAC and SCTS. UK cardiothoracic surgery workforce report, 2019. Available: https://scts.org/wp-content/uploads/2019/01/SCTSworkforce-report-2019.pdf

2 Bhatnagar P, Wickramasinghe K, Wilkins E, et al. Trends in the epidemiology of cardiovascular disease in the UK. Heart 2016;102:1945-52.

3 Viergever RF, Olifson S, Ghaffar A, et al. A checklist for health research priority setting: nine common themes of good practice. Health Res Policy Syst 2010;8:36.

4 Cowan K, Oliver S. The James Lind alliance Guidebook. version 5, 2013. http://www.jlaguidebook.org/pdfguidebook/guidebook.pdf

5 JLA. JLA Guidebook. Available: https://www.jla.nihr.ac.uk/jlaguidebook/

6 JLA. Heart surgery priority setting partnership protocol version 3.0. Available: https://jla.nihr.ac.uk/priority-setting-partnerships/heartsurgery/downloads/Heart-Surgery-PSP-Protocol.pdf

7 Kongsved SM, Basnov M, Holm-Christensen K, et al. Response rate and completeness of questionnaires: a randomized study of Internet versus paper-and-pencil versions. J Med Internet Res 2007;9:e25.

8 Cochrane Library. Cochrane database of systematic reviews. Available: https://www.cochranelibrary.com/cdsr/table-of-contents

9 Reichenspurner $\mathrm{H}$. The evolution of modern cardiac surgery and the necessity to change. Innovations 2016;11:79-83.

10 Gallagher M, Hares T, Spencer J, et al. The nominal group technique: a research tool for general practice? Fam Pract 1993;10:76-81.

11 Murphy G, Kumar T, Lai F, et al. Determining the future of cardiac surgery research. The Bulletin, Society for cardiothoracic surgery in Great britain and ireland, 2019: 33-5. https://issuu.com/open-box/ docs/scts_bulletin_issue_05?e=2178914/67169914

12 Newsletter Hospital Healthcare Europe. Improving cardiac surgery benefits through key research, 2019.

13 Selby JV, Beal AC, Frank L. The patient-centered outcomes research Institute (PCORI) national priorities for research and initial research agenda. JAMA 2012;307:1583-4. 